\title{
Reflexões sobre a aplicabilidade da doutrina das questões políticas à realidade brasileira
}

\author{
Fabrício Dani de Boeckel ${ }^{\star}$
}

\section{INTRODUÇÃO}

É tema palpitante, nos dias atuais, a "importação" de doutrinas e institutos jurídicos estrangeiros, que passam a ser aplicados em nosso país, por vezes sem o devido cuidado no sentido de adaptálos à realidade brasileira. Esse "transplante" de doutrinas e instituições é ainda mais questionável quando os países de origem e de destino pertencem a famílias distintas (Common Law e Civil Law). A doutrina das questões políticas, surgida e desenvolvida numa realidade anglo-americana, é claro exemplo disso.

Mostra-se oportuno, então, verificar as diferenças de contexto existentes entre esses países, sejam elas de natureza cultural, sociológica, institucional, etc. Essa análise permitirá uma reflexão acerca da conveniência e da possibilidade de aplicação da doutrina ou instituto estrangeiro a uma realidade geralmente bastante diversa.

Por essas razões, o presente trabalho tem como foco principal o estudo das condições sob as quais se criou e se desenvolveu a "doutrina das questões políticas", bem como da realidade existente nos países integrantes da família Civil Law, tudo com o objetivo de extrair algumas conclusões concernentes à possibilidade de aplicação da mencionada doutrina no contexto brasileiro.

Portanto, as reflexões constantes do trabalho buscam, antes de mais nada, analisar a viabilidade de importação da referida doutrina, sem a pretensão de conceituar, de forma definitiva, o que sejam "questões políticas" e "questões

\footnotetext{
- Advogado formado e laureado pela Faculdade de Direito da UFRGS; mestrando e professor substituto na mesma Faculdade; juiz leigo do $2^{\circ}$ Juizado Especial Civil.
} 
jurídicas", definição essa que daria margem a infindáveis discussões, distantes do objetivo traçado e incompatíveis com os limites estabelecidos para o trabalho.

Assim, optou-se por dividir o estudo em duas partes, na primeira delas abordando a doutrina das questões políticas em seu contexto de origem, isto é, nos países de Common Law, enquanto na segunda será examinada a realidade dos países de Civil Law, especificamente naqueles aspectos que têm relevância para a aferição da (in)compatibilidade com a mencionada doutrina, entre eles a cumulação das funções de criar direito e fazer política, presente no modelo romano-germânico e ausente no anglo-americano.

\section{PARTE I - A DOUTRINA DAS QUESTÕES POLÍTICAS NOS PAÍSES DE COMMON LAW}

A political question doctrine tem origem anglo-americana. Portanto, foi desenvolvida tendo em vista a realidade própria do Common Law.

$\mathrm{Na}$ verdade, mais correto seria apresentar as peculiaridades atinentes a cada um dos principais países de Common Law, nomeadamente Estados Unidos e Inglaterra, devido às inúmeras diferenças que poderiam aqui ser exploradas. Entretanto, em razão dos limites impostos ao trabalho, uma simples análise genérica, das mais elementares características comuns a essa família anglo-americana, já será suficiente para o efeito de possibilitar uma comparação frente ao Civil Law, o que é o verdadeiro objetivo deste estudo.'

Apenas ressalte-se que a separação entre matérias de governo e matérias de direito surgiu no período medieval inglês, com a distinção entre gubernaculum e jurisdictio, assim delimitando o campo de atuação do Rei e oferecendo obstáculo ao absolutismo monárquico. Porém, foi nos Estados Unidos que a political question doctrine se desenvolveu, até tomar os contornos atuais, após o julgamento de inúmeros casos que expressamente consagraram essa doutrina. ${ }^{2}$

Feitos esses breves registros, passa-se a examinar algumas características gerais próprias do modelo anglo-americano.

1 Diante dessa intencional omissão, remete-se o leitor à seguinte obra, que analisa com precisão o assunto: McILWAIN, Charles Howard. Constitucionalismo Antiguo y Moderno, traduzido para o espanhol por Juan José Solozábal Echavarría. Madri: Centro de Estudios Constitucionales, 1991.

2 Para uma análise mais aprofundada dos aspectos históricos e dos julgados mais importantes a respeito do tema: McILWAIN, Charles Howard. Constitucionalismo Antiguo y Moderno, traduzido para o espanhol por Juan José Solozábal Echavarría. Madri: Centro de Estudios Constitucionales, 1991, e; MELLO, Cláudio Ari. Democracia Constitucional e Direitos Fundamentais. Porto Alegre: Livraria do Advogado, 2004. 


\section{A não cumulação das funções de criar direito e fazer política}

Examinando a divisão das funções a serem exercidas pelos vários poderes estatais, facilmente percebe-se que nos países de Common Law há nítida separação entre as atribuições de criar direito e de fazer política. ${ }^{3}$

O direito, nesses Estados, tem grande enraizamento cultural, sendo produto da argumentação racional que se desenvolve no campo do "processo devido" (due process of law), constituindo-se ao mesmo tempo fruto e também fator viabilizador do consenso social. ${ }^{4}$ Em um segundo momento, os precedentes assim obtidos passam a de certo modo orientar comportamentos, embora isso ocorra de forma muito mais branda (e por que não dizer mais "precária"?) do que nos países de Civil Law. Portanto, considerando que ao Poder Judiciário cabe a condução do processo e a resolução do conflito, a esse mesmo poder resta garantida a primazia na criação do direito.

A política, por outro lado, é matéria reservada às instâncias representativas da população, compostas de forma eletiva. Nesse campo concentram-se as discussões de natureza ideológica, caracterizadas por uma maior mobilidade de opiniões, assim submetendo os rumos políticos da sociedade às escolhas feitas pela maioria parlamentar.

A distinção entre as questões políticas e as questões jurídicas decorre, no Common Law, de um consenso social. Mais do que isso, a separação entre essas questões de natureza diversa é facilitada pela circunstância de que cada um dos poderes estatais adota uma postura contida, de não intervenção nas csferas próprias dos outros poderes. Assim, a simples pesquisa a respeito da "fonte" emanante de certo ato/decisão ajuda a decifrar sta natureza.

Por óbvio, tal critério distintivo não oferece garantias no sentido de impedir os excessos por parte de cada um dos poderes estatais, mas representa elemento simplificador e, por consequiência, facilitador dessa postura de auto-restrição, uma vez que já embasaḑo na presunção de que as

3 SOUZA JUNIOR, Cezar Saldanha. A Supremacia do Direito no Estado Democrático e seus Modelos Básicos. Tese para concurso a professor titular, junto ao Departamento de Direito do Estado - Área de Teoria Geral do Estado, da Faculdade de Direito da Universidade de São Paulo. Porto Alegre, novembro de 2002, p. 120/121.

4 SOUZA JUNIOR, Cezar Saldanha. A Supremacia do Direito no Estado Democrático e seus Modelos Básicos. Tese para concurso a professor titular, junto ao Departamento de Direito do Estado - Área de Teoria Geral do Estado, da Faculdade de Direito da Universidade de São Paulo. Porto Alegre, novembro de 2002, p. 122. 
questões políticas são tratadas pelo Parlamento e as questões jurídicas estão restritas ao campo judicial. Partese já da idéia de que existe uma separação de funções, e os excessos são excepcionais, ao contrário do que ocorre no Civil Law, onde é indispensável a análise, sempre mais profunda e difícil, da natureza de cada "questão", pois tanto as jurídicas quanto as políticas têm origem num mesmo poder do Estado, impedindo a utilização desse critério formal.

Entretanto, não se pode negar que esse critério deve, necessariamente, ser aliado a outros mais complexos, capazes de demonstrar os excessos cometidos por qualquer dos poderes, assim possibilitando o exercício de controle por parte dos demais.

Como já foi ressaltado na parte introdutória, o objetivo do presente estudo não envolve a propositura de conceito ou definição a respeito de o que sejam questões jurídicas e questões políticas (e para tanto seria obrigatória a análise de todos esses critérios distintivos), mas sim a demonstração de que a diversidade social, cultural, institucional, etc. deve ser considerada antes da importação de doutrina estrangeira. Portanto, extrapola os limites do trabalho o exame acerca dos critérios viabilizadores de um conceito abstrato das questões políticas e das questões jurídicas. Mais importante, de acordo com a linha de raciocínio estabelecida para o estudo, é a análise dessas diferenças contextuais entre o Common Law e o Civil Law.

\section{Self restraint}

Para o normal funcionamento do Common Law é necessário que cada Poder Estatal adote postura autorestritiva, respeitando os limites divisórios em relação aos demais.

Por um lado, isso significa que o Judiciário deve restringir sua atuação ao campo do direito, sobre o qual possui primazia, não adentrando em questões de natureza política, ${ }^{5}$ que competem ao Parlamento. E inúmeras são as justificativas para essa postura contida da Justiça, dentre as quais se pode mencionar, exemplificativamente: a) o processo judicial, meio através do qual atua, não se presta à definição dos objetivos a serem alcançados pela sociedade, muito menos é apto para a ampla e irrestrita concretização desses fins, após definidos; b) falta legitimidade aos órgãos jurisdicionais para realizar essas tarefas, que devem ser desempenhadas, em uma sociedade democrática, pelos representantes do povo, devidamente eleitos; c) as moti-

5 Quando se aborda exclusivamente a auto-restrição por parte do Poder Judiciário, podese utilizar a expressão judicial self restraint. Sobre o tema: CANOTILHO, José Joaquim Gomes. Direito Constitucional e Teoria da Constituição, 2. ed. Coimbra: Almedina, 1998, p. 1170/1171. 
vações ideológicas, próprias da política e imprescindíveis à realização do bem comum, são incompatíveis com uma das principais características do Judiciário, consistente na imparcialidade.

O Parlamento, por outro lado, limita sua atuação às questões políticas, não tendo qualquer pretensão no sentido de criar direito. Este último surge a partir do devido processo jurídico, e não do processo legislativo, como ocorre nos países que seguem a tradição romano-germânica.

A auto-restrição do Parlamento é consequiência da idéia de que a tarefa de dizer e criar o direito cabe aos juízes. As decisões judiciais passam a ser vistas como paradigmas para a solução dos casos surgidos posteriormente, sendo desnecessária a atividade legislativa sob esse aspecto, pois a noção de justiça no Common Law está dissociada de uma obrigatória vinculação ao princípio da legalidade, estando condicionada, isto sim, à observância do devido processo jurídico.

Essa postura também se justifica através de vários fatores, entre os quais dois merecem especial destaque: a) as escolhas feitas pelo Parlamento representam (ou ao menos deveriam representar) a vontade da maioria do povo, enquanto o ordenamento jurídico de uma sociedade democrática tem como pressuposto inarredável também o respeito às minorias. A confusão entre essas esferas poderia acarretar uma ditadura da maioria, em que esta detivesse o monopólio tanto da criação do direito quanto das escolhas políticas; b) os juízes têm conhecimento técnico que lhes permite chegar mais próximo da efetiva realização da justiça (valor intimamente ligado à idéia de direito) do que os representantes eleitos pelo povo às vezes com base em aspectos meramente ideológicos, de carisma, etc.

Tudo que foi mencionado acima serve para demonstrar uma característica própria e fundamental do Common Law: a existência de uma self restraint recíproca entre os poderes estatais. Isso significa que a autorestrição adotada por um poder frente às funções atribuídas aos demais é uma "via de mão dupla". É condição para o equilíbrio e para a harmonia entre os poderes estatais que não apenas um deles se porte de forma contida, mas sim que essa postura seja a regra entre todos eles.

\section{PARTE II - APLICABILIDADE DA DOUTRINA DAS QUESTÕES POLÍTICAS AOS PAÍSES DE CIVIL LAW}

Analisada a problemática das questões políticas e das questões jurídicas no âmbito do Common Law, local de surgimento da doutrina em pauta, convém agora comparar as principais características acima estudadas com a situação existente nos países que seguem o modelo romanogermânico. Essa tarefa será realizada nos dois próximos capítulos.

O terceiro e último capítulo desta segunda parte do trabalho tem objetivo um pouco diverso, qual seja, o de 
apresentar os mecanismos adotados por países de Civil Law para permitir certa separação no trato dessas questões, assim procurando evitar maiores conflitos entre os Poderes Estatais.

\section{Cumulação de funções no Poder Legislativo}

Ao invés da nítida separação entre as funções de fazer política e de criar direito, típica do Common Law, nos países que seguem o modelo romanogermânico percebe-se que essas duas funções são tradicionalmente atribuídas, com primazia, a um único poder estatal: o Legislativo.

Quanto à política, inexiste diferença significativa entre o Civil Law e o Common Law, pois em ambos o desempenho de tal função compete ao Poder Legislativo. O que realmente diferencia esses dois modelos é o fato de que, no primeiro deles, também ao Congresso é atribuída, com primazia, a tarefa de criar o direito.

Ao princípio da legalidade é conferida maior importância pelos países de modelo romano-germânico, que adotam a lei como fonte primeira do direito. Não se pretende negar, com isso, que o Judiciário também crie direito; ${ }^{6}$ apenas se afirma que a primazia no exercício dessa função é atribuída ao Legislativo.

Em geral, a tarefa desempenhada pelo Poder Judiciário consiste em aplicar ao caso concreto as normas de um ordenamento jurídico criado primordialmente através do processo legislativo. O exercício da função criadora de direito pelo juiz em regra é subsidiário, ou seja, admitido quando a lei não forneça os elementos necessários ou suficientes ao julgamento da causa, pois ao magistrado é defeso abster-se de proferir decisão, esteja o caso devidamente regrado ou não. Afora isso, evidente que a própria interpretação exige escolhas a serem feitas pelo magistrado, porém sempre devendo se manter dentro dos limites traçados pela lei.

O Legislativo, por outro lado, exerce ambos os papéis: cria direito e faz política. Surge, então, a primeira

6 A respeito da criação do direito pelo juiz, destaque-se a lição de Mauro Cappelletti: "A resposta dada neste ensaio à indagação de se a tarefa do juiz é interpretar ou criar o direito, posiciona-se no sentido de que o juiz, inevitavelmente, reúne em si uma e outra função, mesmo no caso - que constitui, quando muito, regra não sem muitas exceções em que seja obrigado a aplicar lei uma (sic) preexistente. Nem poderia ser de outro modo, pois a interpretação sempre implica um certo grau de discricionariedade e escolha e, portanto, de criatividade (...)". Ainda segundo o consagrado processualista italiano, o "verdadeiro perigo a prevenir não está, portanto, em que os juízes sejam criadores do direito e como tais se apresentem, mas que seja pervertida a característica formal essencial, isto é, o 'modo' do processo jurisdicional” (CAPPELLETTI, Mauro. Juizes Legisladores?, traduzido por Carlos Alberto Alvaro de Oliveira. Porto Alegre: Fabris, 1993/Reimpressão 1999 , p. 128/129 e 132, respectivamente). 
dificuldade para distinguir as questões jurídicas das questões políticas em um contexto de Civil Law, uma vez que a "fonte" de todas elas concentra-se num mesmo órgão. Esse critério, portanto, deixa de ter qualquer utilidade para averiguar a natureza de uma determinada questão, quando se trata de Estado que segue o modelo romano-germânico.

\section{Equilíbrio entre os poderes} e legitimidade democrática do Judiciário

Evidente que essa cumulação de funções pode ter reflexos sobre o equilíbrio entre os Poderes. Afinal, inegavelmente o Legislativo assume dimensão maior nos Países que adotam o Civil Law.

Mas não é apenas essa cumulação das funções de criar direito e fazer política que tem acarretado o crescimento do Poder Legislativo. Outro aspecto a considerar é o aumento das funções (e conseqüente maior intervencionismo) do Estado contemporâneo, em que o rol de direitos fundamentais é cada vez mais extenso e sua concretização mais dependente de ações governamentais positivas. ${ }^{7}$ O governo passou a tratar de matérias que antes estavam fora de sua esfera de atuação. Por óbvio, essa postura mais intervencionista do Executivo e do Legislativo ressalta a importância de um controle eficiente, a ser exercido sobre esses poderes.

O Judiciário, responsável por essa fiscalização, deve acompanhar o crescimento dos demais poderes, sob pena de não mais conseguir conter os excessos dos outros dois gigantes (Legislativo e Executivo-). ${ }^{8}$ Tal atitude é necessária ao equilíbrio dos Poderes Estatais. Com isso não se pretende insinuar, todavia, que o Judiciário deva fazer uso dos meios próprios da política para se igualar aos demais poderes.

7 Nesse sentido: “(...) uma das características comuns à sociedade moderna consiste no extraordinário crescimento do Poder Judiciário. Esse fenômeno é paralelo a outro crescimento, pelo qual o primeiro foi em muitos modos estimulado ou verdadeiramente causado: o crescimento - em dimensões sem precedentes - dos 'poderes políticos' no moderno estado 'social' ou 'promocional' (...)" (CAPPELLETTI, Mauro. Juizes Irresponsáveis?, traduzido por Carlos Alberto Alvaro de Oliveira. Porto Alegre: Fabris, 1989, p. 19).

8 Ao descrever a encruzilhada em que se encontravam os tribunais diante do crescimento acelerado dos demais poderes, Cappelletti afirma: "Eles devem de fato escolher uma das duas possibilidades seguintes: a) permanecer fiéis, com pertinácia, à concepção tradicional, tipicamente do século XIX, dos limites da função jurisdicional, ou b) elevar-se ao nível dos outros poderes, tornar-se enfim o terceiro gigante, capaz de controlar o legislador mastodonte e o leviatanesco administrador" (CAPPELLETTI, Mauro. Juizes Legisladores?, traduzido por Carlos Alberto Alvaro de Oliveira. Porto Alegre: Fabris, 1993/Reimpressão 1999, p. 47). 
Ou seja, deve se manter dentro da sua esfera de competências, consistente na proteção do ordenamento jurídico vigente, das coletividades e dos indivíduos aos quais são outorgados direitos subjetivos, bem como exercer esse controle segundo as normas que disciplinam sua atuação, sempre preso às limitações que o processo judicial the impõe: condicionado ao princípio dispositivo (ne procedat iudex ex officio), garantindo às partes envolvidas ampla defesa e contraditório, tudo através do devido processo jurídico.

Por outro lado, o desenvolvimento do campo da política, ocasionando maior intervencionismo, acaba por acarretar maiores conflitos entre as ações legislativas ou executivas (especialmente em se tratando de realizações de natureza social, que dependem de prestação positiva do Estado, destinada a suprimir desigualdades, proporcionar melhores condições de vida aos necessitados, garantir oportunidade de trabalho ao maior número de cidadãos possível, etc.) e alguns direitos subjetivos constitucionalmente albergados. E para que esses direitos sejam efetivamente protegidos, o Poder Judiciário não pode ser afastado completamente da discussão acerca das conseqüências da decisão política.

Ao Judiciário cabe a constatação de que determinada política pública fulmina direitos individuais, devendo oferecer, ao indivíduo, a proteção contra esses excessos. A circunstância de não ser composto por representantes eleitos pelo povo não retira do Poder Judiciário a legitimidade para se contrapor a atos políticos, que dizem com os objetivos traçados para a sociedade, pois sua legitimidade não assenta na vontade da maioria, mas sim está embasada em outro aspecto igualmente fundamental numa democracia: o respeito às minorias, ${ }^{9}$ que no campo político geralmente são derrotadas (exceto quando uma minoria tiver interesses similares a outras minorias, e, unidas, acabem formando uma maioria).

É altamente questionável se todo e qualquer juiz ou tribunal tem idêntica legitimidade para exercer esse tipo de controle sobre os atos políticos, mas esse assunto não será tratado no presente capítulo, e sim no próximo. Por ora, apenas interessa fomentar a discussão sobre a possibilidade de controle das decisões políticas no âmbito do Civil Law, a ser exercido pelo

9 Ruy Rosado de Aguiar Júnior assim justifica a legitimidade democrática do Judiciário: "A opinião da maioria pode ser incoerente com o sistema, e por isso desconsiderada pelo Juiz, que tem um compromisso de coerência. É por isso que o Juiz pode decidir contra a opinião pública, ou afastar a lei, ainda que representem a vontade da maioria, pois aquela pode ofender a lei, e esta, vulnerar a Constituição. Ao lado do princípio democrático de respeito à vontade da maioria, também existe o que impõe o respeito à minoria" (AGUIAR JÚNIOR, Ruy Rosado de. Responsabilidade Política e Social dos Juizes nas Democracias Modernas. In.: Ajuris, n. 70, julho de 1997, p. 31). 
Judiciário ou parte dele (por exemplo, o Supremo Tribunal Federal), para que no capítulo seguinte se possa questionar as formas pelas quais isso pode ser feito sem prejuízo do equilíbrio entre os poderes e sem intromissão indevida em funções alheias.

Para finalizar este capítulo, importante destacar que o controle judicial das leis e dos atos administrativos não pode, de forma alguma, estar embasado na discordância em relação às motivações que levaram o legislador ou o administrador a agir. O juiz não pode aplicar o "preciso raciocínio jurídico" (do certo-errado, lícito-ilícito, válido-inválido) às questões políticas, pois esse método só admite uma resposta correta para cada caso: não oferece solução para casos em que se lida com situações igualmente boas, ou ainda quando se tem que optar por um "mal menor" dentre os muitos males iminentes. ${ }^{10}$ De outra parte, ao Judiciário não é facultado exercer raciocínio político, sob pena de exorbitar as atribuições decorrentes de sua legitimidade democrática. Daí a conclusão de que a atividade do Judiciário deve se limitar à aplicação do "raciocínio jurídico" às questões jurídicas. Todavia, por vezes estas últimas se originam de atos políticos que contrariam preceitos éticos (valores albergados pelo ordenamento), e a avaliação da compatibilidade do ato com o direito é inafastável do controle judicial. Mas ainda resta saber de que forma isso deve ser feito, bem como se essa atribuição deve ser conferida a todo e qualquer juiz ou apenas a uma parte do Poder Judiciário.

\section{Tentativas de separação entre as questões políticas e as questões jurídicas}

Nos dois capítulos anteriores, procurou-se trazer à tona elementos que de certa forma pudessem justificar, no Civil Law, uma interferência do Judiciário em questões de natureza política. Entretanto, ao longo do trabalho foram sendo também mencionadas restrições que afetam a atividade jurisdicional, por exemplo: subordinação a normas de processo civil, condições exigidas para que a atuação do juiz tenha um lastro de legitimidade democrática, etc.

10 Manoel Gonçalves Ferreira Filho, após destacar que os magistrados, em regra, não estão preparados para decidir conforme reclama a judicialização, especialmente por thes faltar o tino administrativo, que é adquirido com a experiência, não através do estudo dos livros, conclui: "Ora, o juiz está habituado a essa separação radical, preparado que foi para separar o legal do ilegal. Em razão disto, costuma ter uma visão maniqueista das coisas. Ignora que a opção do administrador sopesa alternativas complexas, às vezes entre vários males" (FERREIRA FILHO, Manoel Gonçalves. A Constituição de $1988 \mathrm{e} \mathrm{a}$ Judicialização da Política. In: Revista da Faculdade de Direito da Universidade Federal do Rio Grande do Sul, v. 12, p. 194, 1996. 
Agora serão expostas algumas tentativas (já experimentadas) no sentido de separar o tratamento das questões políticas e das questões jurídicas, ainda no âmbito da Família romano-germânica. Trata-se, basicamente, de soluções institucionais adotadas por certos países, que igualmente devem ser muito bem analisadas antes de se pretender aplicá-las à realidade brasileira. Contudo, evidentemente são soluções mais próximas de nossa realidade do que a norte-americana ou a inglesa, nações pertencentes à família do Common Law.

Um dos exemplos mais nítidos, no Civil Law, dessa preocupação com os limites do Poder Judiciário e do cuidado em evitar a interferência deste em questões de natureza política é o francês. Inicialmente, importante destacar um aspecto histórico característico da França, qual seja, a desconfiança presente na sociedade em relação aos juízes e o medo de que eles exorbitassem as suas funções. Aqui uma primeira diferença existente entre Brasil e França: em nosso país, o Judiciário tradicionalmente goza de conceito infinitamente mais elevado junto à população se comparado aos demais Poderes Estatais, sempre vistos com extrema reserva e descrédito."

Independentemente dessa ressalva, deve-se analisar a (tentativa de) solução adotada pelo referido país europeu, com o objetivo de impedir (ou ao menos atenuar) a chamada "judicialização da política".

$\mathrm{Na}$ França foi criado um modelo de "dualismo jurisdicional", pretendendo que o contencioso administrativo significasse um campo próprio à resolução das questões mais próximas da política e impedindo que ao Poder Judiciário chegassem litígios envolvendo assuntos dessa natureza. Existe, também na França, uma distinção entre "lei" e "regulamento": 12 o que não está expressamente sob o domínio da lei é matéria regulamentar e, por conseqüência, passível de controle somente por parte dos tribunais administrativos/Conselho de Estado.

Além disso, o controle prévio de constitucionalidade existente na França restringe, ainda mais, os poderes do Judiciário, uma vez que a discussão sobre a compatibilidade das leis em relação à Carta Constitucional é

11 É essa a constatação feita por Manoel Gonçalves Ferreira Filho: "No Brasil, como já apontei no artigo mencionado, o apelo à judicialização tem algumas razões fáceis de identificar". E continua: "Embora não haja - que se saiba - qualquer doutrina por detrás disto, o Judiciário goza de uma confiabilidade que os Poderes 'políticos' Legislativo e Executivo perderam. Estes são olhados com desconfiança pela opinião pública, alimentada pelos meios de comunicação de massa" (FERREIRA FILHO, Manoel Gonçalves. A Constituição de 1988 e a Judicialização da Política. In.: Revista da Faculdade de Direito da Universidade Federal do Rio Grande do Sul, v. 12, p. 193, 1996.

12 Sobre o tema: FERREIRA FILHO, Manoel Gonçalves. Do Processo Legislativo, 5. ed. rev., ampl. e atual. São Paulo: Saraiva, 2002, p. 172-182. 
esgotada antes que pudesse ser levada ao âmbito judicial, ou seja, antes mesmo da promulgação da lei. Posteriormente, é vedado aos juízes afastar a aplicação das leis sob o argumento da inconstitucionalidade.

Esses, em suma, os principais mecanismos criados na França para coibir a judicialização da política. Outros países, contudo, resolveram adotar soluções diversas quanto a esse problema, típico do Civil Law. A Alemanha, por exemplo, criou um "órgão de controle geral de poderes", o Tribunal Constitucional. Tal órgão tem atribuições próprias, destacando-se a aferição de compatibilidade das regras jurídicas em face de normas superiores albergadas pela Constituição, tarefa que, segundo Otto Kimminich, é a pedra angular do Estado de Direito, impedindo a existência de uma ditadura imposta pela maioria parlamentar. ${ }^{13}$

Inegavelmente, a esfera de atuação do Bundesverfassungsgericht abrange tanto questões jurídicas quanto políticas. A "judicial self restraint" aplicada ao Tribunal Constitucional não implica em que o mesmo deixe de exercer o controle sobre as decisões políticas; significa, isto sim, que não deve dar início a processos políticos, não empreender iniciativas movido por razões políticas. A prática reiterada da "interpretação conforme a Constituição", bem como o entendimento consolidado no Tribunal Constitucional quanto à impossibilidade de se apreciar, no âmbito jurisdicional, a conveniência e a adequação de uma lei (limitando a discricionariedade do legislador apenas nos casos de notória arbitrariedade ou de ofensa às decisões valorativas do constituinte) demonstram, de acordo com Otto Kimminich, a auto-restrição do Bundesverfassungsgericht. ${ }^{14}$ Destaque-se, ainda, outra limitação imposta ao Tribunal Constitucional, consistente na dependência de que seja provocado para só então poder atuar.

Além de ser o guardião da Constituição e de ter parte da sua legitimidade democrática embasada na função de assegurar o respeito às minorias (como é próprio de todo o Poder Judiciário), deve-se mencionar ainda outro fator que legitima a atuação do Tribunal Constitucional alemão também em temas políticos: sua forma de composição é, de certo modo, política; existe a preocupação em manter o equilíbrio entre as diversas correntes políticas na composição do Bundesverfassungsgericht. ${ }^{15}$

13 KIMMINICH, Otto. Jurisdição Constitucional e Princípio da Divisão de Poderes. In.: Revista de Direito Público, n. 92, outubro-dezembro de 1989, p. 19.

14 KIMMINICH, Otto. Jurisdição Constitucional e Princípio da Divisão de Poderes. In.: Revista de Direito Público, n. 92, outubro-dezembro de 1989, p. 27.

15 A respeito da forma de composição do Tribunal Constitucional alemão: HESSE, Konrad. Elementos de Direito Constitucional da República Federal da Alemanha, traduzido para o português (a partir da $20^{\mathrm{a}}$ edição alemã) por Luís Afonso Heck. Porto Alegre: Sergio Antonio Fabris Editor, 1998, p. 488/489. 
Restaria discutir, agora, se o Tribunal Constitucional integra o Poder Judiciário ou se constitui um poder autônomo, estranho a ele. Entretanto, por óbvio não há como resolver essa questão, extremamente controvertida, no presente trabalho, que tem objeto diverso. Essa discussão exigiria complexa e demorada análise, incompatível com os limites traçados para este estudo. O que importa, de fato, é registrar que a primazia dos poderes políticos no trato de questões dessa mesma natureza não exclui, por completo, a possibilidade de controle externo, realizado por órgão cuja natureza não é essencialmente política, e sim jurídica.

\section{CONCLUSÕES}

É evidente a diferença entre o modelo romano-germânico e o angloamericano. No primeiro, o Congresso acumula as funções de criar direito e fazer política. Ambas são realizadas através do processo legislativo, cuja importância ganha maior vulto em razão do destaque que é conferido ao princípio da legalidade. No segundo, o direito é criado pelos juízes, através do devido processo jurídico, enquanto a política é tarefa atribuída ao Parlamento.

Assim, nos Estados Unidos e na Inglaterra, diante dessa clara divisão de funções entre os poderes estatais, é possivel exigir destes uma postura de auto-restrição, para o efeito de que cada um limite sua atuação apenas ao campo que lhe é próprio. Portanto, a self restraint é, acima de tudo, recíproca. Além disso, é condição para que seja mantido o equilíbrio entre os poderes.

No Brasil e nos demais países de Civil Law, onde o Poder Legislativo concentra essas funções (criar direito e fazer política), é inviável pretender que o Judiciário não aprecie a lei, pois este é o meio através do qual se produz tanto o direito quanto a política. E aí surge a dificuldade em distinguir o que seja questão política e o que seja questão jurídica, já que a fonte é a mesma. Por outro lado, o pressuposto lógico da self restraint, isto é, a reciprocidade, fica de certo modo abalada nesse contexto, uma vez que não há como vislumbrar auto-restrição por parte do Legislativo, poder hipertrofiado que detém a primazia na criação do direito e da política.

Talvez esses fatores já fossem suficientes para demonstrar a impossibilidade de aplicação da political question doctrine à realidade brasileira. Porém, ressalte-se que as conclusões da mencionada doutrina vêm sendo atenuadas até mesmo nos países de Common Law, onde se reconhece que, ao menos quando direitos fundamentais forem ameaçados ou violados, o Judiciário deve atuar, importe isso em restrição a medidas políticas ou não.

Afinal, o direito, enquanto ponte que harmoniza ética e política, tem seu espaço de atuação limitado às situações em que esses dois campos da natureza humana entram em conflito. Havendo colisão entre eles, é inafastável a 
atuação judicial com o objetivo de eliminar as arestas e garantir a coexistência de ambos. Por isso, não se pode, a priori, impedir que o Judiciário aprecie todas as questões que the forem submetidas, verificando, caso a caso, se os valores éticos não estão sendo totalmente desconsiderados por determinada política, ou vice-versa. Isso é assegurado pelo princípio do judicial review, segundo o qual nenhuma lesão ou ameaça a direito poderá ser excluída da apreciação do Judiciário. Assim, é condição indispensável para o exercício da função harmonizadora entre política e ética, que a atuação judicial não seja previamente excluída, em abstrato, sem análise do caso concreto eventualmente violador desse equilibrio.

Além dessa função, o direito ainda exerce outra de fundamental importância: serve de instrumento para a atuação política do Estado. Portanto, mesmo que a questão discutida não contrarie valores éticos (e, por conseqüência, não exija harmonização a ser exercida pelo direito quanto ao seu "conteúdo"), sob o aspecto "formal" as decisões ou escolhas políticas ericontram-se inteiramente submetidas ao direito, pois para que

\section{REFERÊNCIAS}

AGUIAR JÚNIOR, Ruy Rosado de. Responsabilidade Política e Social dos Juízes nas Democracias Modernas. In Ajuris, n. 70, p. 7-33.: jul. 1997. este instrumento possa ser utilizado devem ser obedecidas as formalidades que lhe são próprias. Daí conclui-se que, mesmo quando o conteúdo da questão é "exclusivamente político", sua validade fica condicionada à observância das formalidades estabelecidas pelo direito, cujo controle compete ao Judiciário. Exemplo claro disso é a decisão política adotada através de Medida Provisória, que deve atender aos pressupostos de relevância e urgência.

Apesar das várias tentativas no sentido de proporcionar tratamento distinto às questões políticas e às questões jurídicas, nos países de Civil Law essa separação é praticamente impossível, já que grande parte dos dispositivos legais traz carga política $\mathrm{e}$ jurídica misturadas. Entretanto, a solução alemã, de criação de um Tribunal Constitucional, em parte atenua os problemas resultantes dessa confusão, na medida em que impede a pulverização do controle das medidas políticas, concentrando-o num único órgão, cuja composição respeita equilíbrio entre as diversas correntes políticas. Agora fica a pergunta: deve-se importar o modelo alemão para o Brasil? A resposta ensejaria outro trabalho...

BALEEIRO, Aliomar. A Função Política do Judiciário. In.: Revista dos Tribunais, v. 756, out. 1998, p. 731-745. 
CAENEGEM, R. C. van. Judges, Legislators and Professors: chapters in European legal history. Cambridge: Cambridge University Press, 1996.

CANOTILHO, José Joaquim Gomes. Direito Constitucional e Teoria da Constituição, 2. ed. Coimbra: Almedina, 1998.

CAPPELLETTI, Mauro. Juizes Irresponsáveis?, traduzido por Carlos Alberto Alvaro de Oliveira. Porto Alegre: Fabris, 1989.

. Juizes Legisladores?, traduzido por Carlos Alberto Alvaro de Oliveira. Porto Alegre: Fabris, 1993/Reimpressão 1999.

CASTRO, Carlos Roberto de Siqueira. O Devido Processo Legal e a Razoabilidade das Leis na Nova Constituição do Brasil. Rio de Janeiro: Forense, 1989.

COMPARATO, Fábio Konder. Ensaio sobre o Juízo de Constitucionalidade de Políticas Públicas. In Revista dos Tribunais, v. 737, março de 1997, p. 11-22.

DWORKIN, Ronald. A Matter of Principle, 9. ed. Cambridge: Harvard University Press, 2000.

FERREIRA FILHO, Manoel Gonçalves. A Constituição de 1988 e a Judicialização da Política. In Revista da Faculdade de Direito da Universidade Federal do Rio Grande do Sul, v. 12, 1996, p. 189-197.
. Do Processo Legislativo, 5. ed. rev., ampl. e atual. São Paulo: Saraiva, 2002.

HESSE, Konrad. Elementos de Direito Constitucional da República Federal da Alemanha, traduzido para o português (a partir da 20. edição alemã) por Luís Afonso Heck. Porto Alegre: Sergio Antonio Fabris Editor, 1998.

KIMMINICH, Otto. Jurisdição Constitucional e Princípio da Divisão de Poderes. In Revista de Direito Público, n. 92, outubrodezembro de 1989, p. 17-33.

MAXIMILIANO, Carlos. Commentarios à Constituição Brasileira. Rio de Janeiro: Jacinto Ribeiro dos Santos, 1918.

McILWAIN, Charles Howard. Constitucionalismo Antiguo y Moderno, traduzido para o espanhol por Juan José Solozábal Echavarría. Madri: Centro de Estudios Constitucionales, 1991.

MEDINA, Llewellyn Davies A. As Chamadas 'Questões Políticas' no Direito Constitucional Brasileiro.

In Revista dos Tribunais, v. 685 , novembro de 1992 , p. 259-261.

MELLO, Cláudio Ari. Democracia Constitucional e Direitos Fundamentais. Porto Alegre: Livraria do Advogado, 2004. 
MENAUT, Antonio-Carlos Pereira. SOUZA JUNIOR, Cezar Saldanha. $A$ Rule of Law o Estado de Derecho. Madri: Marcial Pons, 2003.

SILVA, Carlos Augusto. O Processo Civil como Estratégia de Poder: reflexo da judicialização da política no Brasil. Rio de Janeiro: Renovar, 2004. Supremacia do Direito no Estado Democrático e seus Modelos Básicos. Tese para concurso a Professor Titular, junto ao Departamento de Direito do Estado - Área de Teoria Geral do Estado, da Faculdade de Direito da Universidade de São Paulo. Porto Alegre, nov./ 2002. 